\title{
Observed melt-season snowpack evolution on the Greenland ice sheet
}

\author{
Charalampos Charalampidis and Dirk van As
}

Due to recent warm and record-warm summers in Greenland (Nghiem et al. 2012), the melt of the ice-sheet surface and the subsequent runoff are increasing (Shepherd et al. 2012). About $84 \%$ of the mass loss from the Greenland ice sheet between 2009 and 2012 resulted from increased surface runoff (Enderlin et al. 2014). The largest melt occurs in the ablation zone, the low marginal area of the ice sheet (Van As et al. 2014), where melt exceeds wintertime accumulation and bare ice is thus exposed during each melt season. In the higher regions of the ice sheet (i.e. the accumulation area), melt is limited and the snow cover persists throughout the year. It is in the vast latter area that models struggle to calculate certain mass fluxes with accuracy. A better understanding of processes such as meltwater percolation and refreezing in snow and firn is crucial for more accurate Greenland icesheet mass-budget estimates (Van Angelen et al. 2013).

In May 2012, the field campaign 'Snow Processes in the Lower Accumulation Zone' was organised by the Geological Survey of Denmark and Greenland (GEUS) at the KAN_U automatic weather station $\left(67^{\circ} 0^{\prime} 0^{\prime \prime} \mathrm{N}, 47^{\circ} 1^{\prime} 1^{\prime \prime} \mathrm{W} ; 1840 \mathrm{~m}\right.$ above sea level), which delivers data to the Programme for Monitoring of the Greenland Ice Sheet (PROMICE; Van As et al. 2013) and is one of the few weather stations located in the lower accumulation area of Greenland (Fig. 1, inset). During the expedition, we installed thermistor strings, firn compaction monitors and a snowpack analyser; we drilled firn cores, performed firn radar measurements, gathered meteorological data, dug snow pits and performed dye-tracing experiments. One important objective of the campaign was to understand the thermal variability in the snowpack during the melt season by monitoring with high-precision temperature probes (Campbell Scientific temperature probe, model 107; accuracy: better than $\pm 0.4^{\circ} \mathrm{C}$ over the range -24 to $\left.48^{\circ} \mathrm{C}\right)$.

Six temperature probes were installed in the snowpack of the previous winter at depths of $0.05,0.10,0.20,0.30,0.40$ and $0.70 \mathrm{~m}$ below the surface (Fig. 1). The data from the probes were stored at 30-minute intervals on data loggers, which also triggered additional measurements of radiation-shielded air temperature at $1.10 \mathrm{~m}$, surface albedo and surface-height change due to accumulation and ablation. Emitted longwave radiation was also recorded to be able to calculate the surface temperature assuming snow to be a black-body radiator. The vertical position of the probes relative to the surface, which changes due to ablation and accumulation, was determined by the sonic ranger measurements. Recorded temperatures after the probes surfaced were discarded.

The relatively shallow snowpack $(0.70-0.80 \mathrm{~m})$ was on top of firn of density $\rho>500 \mathrm{~kg} \mathrm{~m}^{-3}$ which had accumulated in the previous years (Fig. 1). In the upper firn we found ice lenses $\left(\rho>800 \mathrm{~kg} \mathrm{~m}^{-3}\right)$ several metres thick. Within the snowpack, two thin ice layers were present, one at $0.30 \mathrm{~m}$

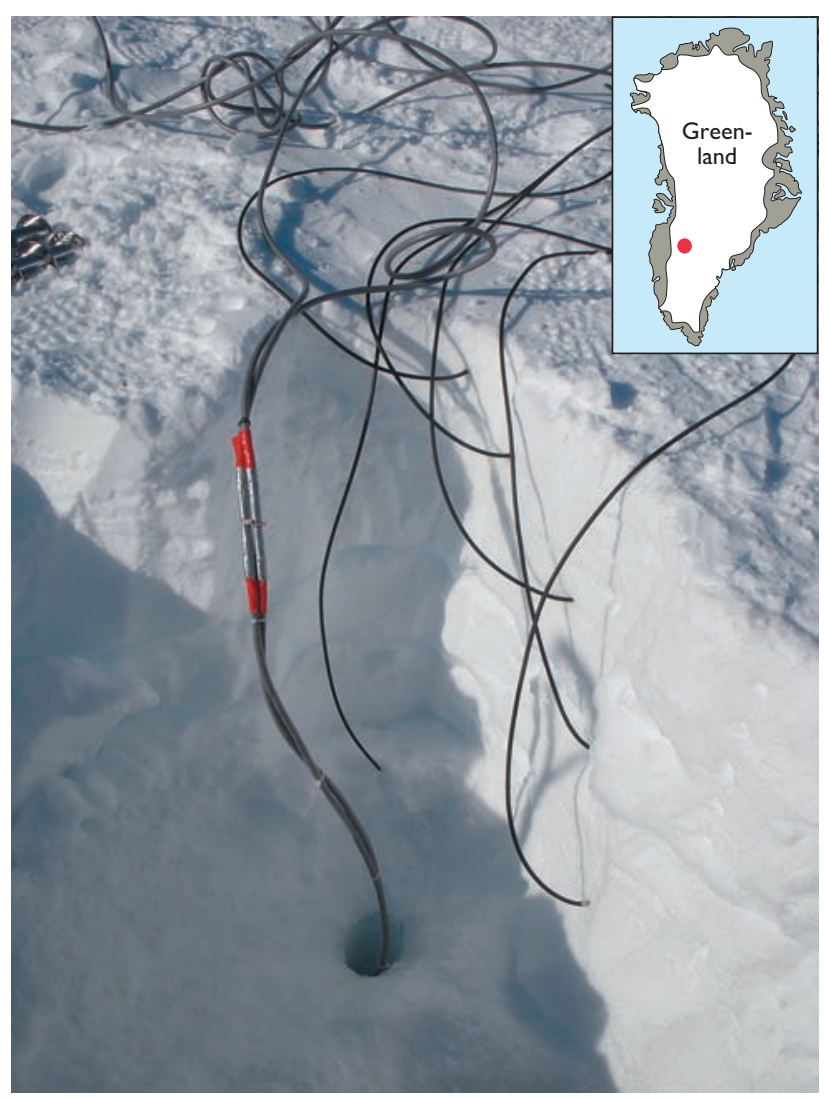

Fig. 1. After the installation of the temperature probes in May 2012 (thin black cables) at the location of KAN_U on the Greenland ice sheet. The thick grey cables are thermistor strings drilled into the firn. The inset map shows the location of the study area. 


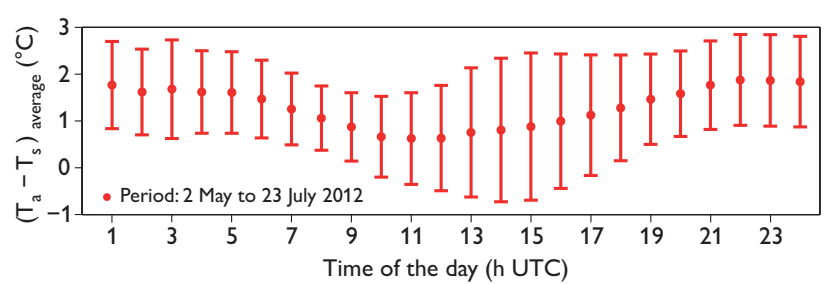

Fig. 2. Average temperature difference between air and surface during the day. The error bars show two standard deviations. Solar zenith time is at 15:08 UTC.

and one at $c .0 .50 \mathrm{~m}$ below the surface, both about $0.01 \mathrm{~m}$ thick. The average density of the snow was determined to be roughly $360 \mathrm{~kg} \mathrm{~m}^{-3}$, yielding an accumulation of $0.25 \pm 0.08$ $\mathrm{m}$ water equivalent (w.e.) since the summer 2011 (Charalampidis et al. 2015). Below, we present observations from the period 02 May to 23 July and interpret the atmosphere-surface interaction and its impact on the subsurface snow layers, with the goal to quantify refreezing in the Greenland accumulation area.

\section{Atmosphere-snow interaction}

The observations reveal a strong similarity between the nearsurface air temperature and the snow-surface temperature with changes of air temparature lagging on average 30-40 minutes behind. Typically, the air remained warmer than the snow surface (Fig. 2), implying a prevailing stable stratification of the near-surface air. At night, the difference was larger $\left(1.6-1.9^{\circ} \mathrm{C}\right)$ due to the reduced sunlight and subsequent cooling of the surface forced by longwave radiation. During the day, the temperature difference was smaller $\left(0.6-1.2^{\circ} \mathrm{C}\right)$ primarily due to solar radiation heating the surface and reducing atmospheric stability. Understandably, when air temperature exceeds $0^{\circ} \mathrm{C}$, the temperature difference can be larger since the surface cannot exceed the melting point.

On 6 May, overcast conditions and atmospheric stillness caused the increase of air temperature above $+6^{\circ} \mathrm{C}$ (Fig. $3 \mathrm{~A}$ ). These were the highest temperatures during the observational period and similar temperatures occurred also on two days in June (3 and 18). With the exception of 6 May, the air temperature remained negative until the last week of May. During this period, the temperature of the upper $0.20 \mathrm{~m}$ of snow followed a pronounced diurnal cycle, which at $0.20 \mathrm{~m}$ lagged about 10 hours behind the variations in surface temperature (Fig. 3B), signifying the low thermal conductivity of snow.

At $1840 \mathrm{~m}$ above sea level, the ice sheet generally experiences low melt rates. When melt occurs, it displays a diurnal cycle following air temperature. A diurnal cycle of positive air temperatures occurred first on 27 May, marking the beginning of the melt season (Fig. 3A). The surface ablated in response to the warm conditions, while the snow temperatures revealed the distinct progression of a warming and thus wetting front moving vertically through the snowpack (Fig. 3B). The temperature at $0.70 \mathrm{~m}$ depth was affected by this 42 hours after surface melt initiated, i.e. an average warming front progression of only c. $17 \mathrm{~mm} \mathrm{~h}^{-1}$. The entire snowpack became temperate after six days of ablation. The slow progression of the warming front indicates a concurrent heterogeneous meltwater infiltration to the firn below (Humphrey et al. 2012).

During the period 8-12 June, sub-freezing air temperatures occurred again (Fig. 3A) and melting ceased. While the upper part of the snowpack remained close to $0^{\circ} \mathrm{C}$, possibly containing liquid water, the deeper levels ( $0.4 \mathrm{~m}$ and below) cooled as heat was conducted downwards into the colder firn. Melt resumed on 13 June, affecting snow temperatures at 0.7 $\mathrm{m}$ after 30 hours (Fig. 3B), which is faster than in the previous melt period due to the reduced measurement depth, and changed snow properties. Thereafter, the snow remained at the melting point until it ablated completely on 11 July.

Between 13 June and 11 July, there were five occasions when the diurnal air/surface temperature cycle was interrupted by periods with warm night-time conditions resulting in enhanced ablation (Fig. 3A). Most notably, during the warm week of 8-14 July when the whole Greenland icesheet surface area was reported to melt (Nghiem et al. 2012), the air temperature at KAN_U remained above $+2^{\circ} \mathrm{C}$ for six days and melt was large. At the same time, the 'Watson River', which drains this section of the ice sheet, experienced the highest discharge in 56 years, judging from the partial destruction of a 1956 bridge near the town of Kangerlussuaq.

\section{Snowpack evolution}

In May, the area received $0.12 \mathrm{~m}$ of fresh snow on top of the existing snowpack (Fig. 4B) and the albedo remained at fresh snow values of $0.8-0.9$ (Fig. 4A). On 27 May, the surface began ablating and by the end of the day $0.05 \mathrm{~m}$ of the fresh snow had melted away. In the period until 8 June the average ablation rate was $0.02 \mathrm{~m} \mathrm{day}^{-1}$, reducing albedo to $c .0 .75$, primarily due to snow metamorphosis.

In principle, the energy needed to make temperate a uniform snowpack $0.7 \mathrm{~m}$ thick at $-10^{\circ} \mathrm{C}$ is equivalent to the energy necessary for melting $0.04 \mathrm{~m}$ of snow at $0^{\circ} \mathrm{C}$ and a density of $360 \mathrm{~kg} \mathrm{~m}^{-3}$. Therefore, the generation of $15 \mathrm{~mm}$ of meltwater and its refreezing within the snowpack raises its temperature to $0^{\circ} \mathrm{C}$. By the beginning of June when the entire snowpack had reached $0^{\circ} \mathrm{C}$, the first $0.15 \mathrm{~m}$ of snow (i.e. c. $50 \mathrm{~mm}$ of meltwater) had ablated. This implies that approximately $70 \%$ of the meltwater either percolated deeper 

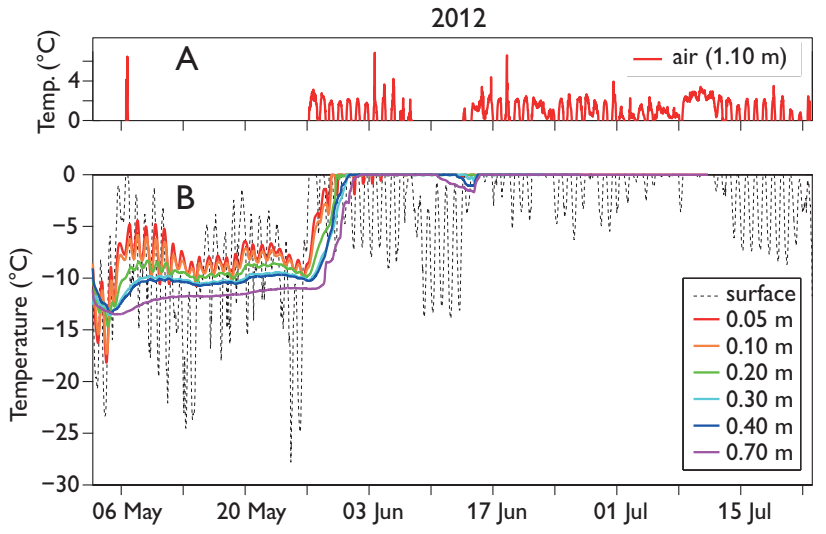

Fig. 3. Observed temperatures of the near-surface atmosphere (A) and (sub)surface (B).
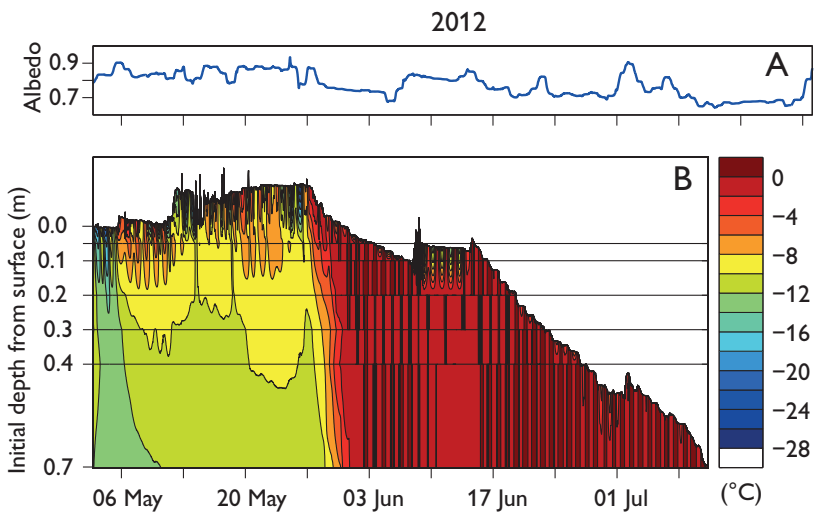

Fig. 4. Observed surface albedo (A) and thermal evolution (B) of the snow pack. The dark red contour signifies $0^{\circ} \mathrm{C}$.
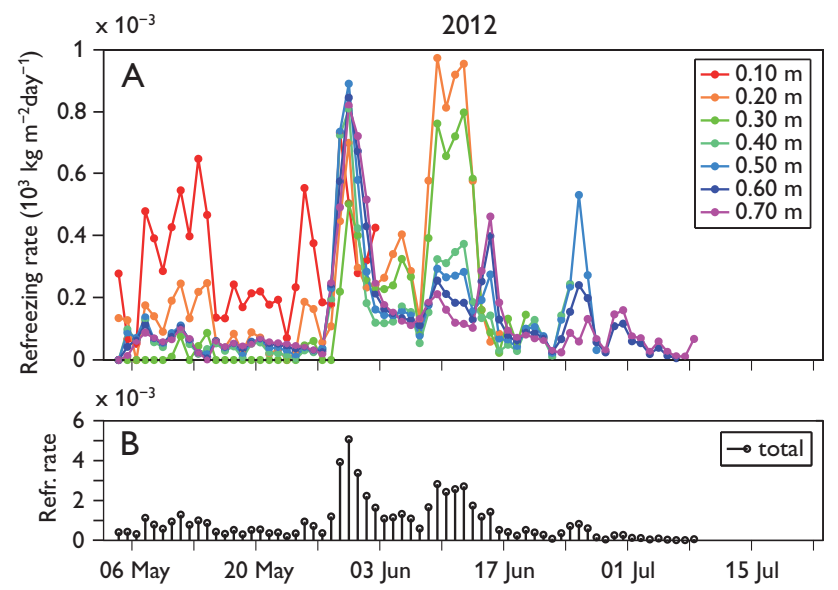

Fig. 5. Calculated refreezing rates in the snow at $0.1 \mathrm{~m}$ spacial resolution (A) and combined (B).

into the firn or was retained in liquid form in the snow by capillary forces. From the beginning of June onward, by lack of cold content, the snowpack was able to respond immedi- ately to surface forcings (Fig. 4B), and all percolating meltwater was routed toward the underlying firn.

The cold conditions and melt pause from 8 to $12 \mathrm{June}$ were accompanied by snowfall resulting in $0.05 \mathrm{~m}$ of fresh snow accumulation (Fig. 4B), thereby increasing the albedo above 0.8 (Fig. 4A). Melt resumed on 15 June with an average ablation rate of $0.03 \mathrm{~m} \mathrm{day}^{-1}$ and with albedo dropping as low as 0.7 , indicative of wet snow. Small snowfall events also occurred in the beginning of July. During the warm days of 9 and 10 July the ablation rate exceeded $0.05 \mathrm{~m} \mathrm{day}^{-1}$, removing the last of the 2011-2012 winter snowpack and revealing the underlying, water-saturated firn. Consequently, the albedo dropped below 0.7 , enhancing melt through the meltalbedo feedback (Box et al. 2012).

\section{Simulated refreezing rates}

A combination of temperature measurements and thermal conductivity simulations reveals the amount of refrozen water in the snow. A heat-conduction model was used to simulate the evolution of subsurface temperatures, using measured surface temperature and surface height change as input. The model was run at temporal and spatial resolutions of 10 minutes and $0.10 \mathrm{~m}$, respectively, and was re-initialised each day by measured temperature profiles at 00:00 UTC. The effective conductivity of the snow is a function of snow density (Sturm et al. 1997) and the specific heat of snow depends on temperature (Yen 1981). Density profiles were initialised based on snow pit density measurements at the installation of the probes and were updated throughout the run taking refreezing into account. The difference between the simulated and measured temperatures at the end of the day is a measure of the added latent heat during the day, and thus of the daily refreezing rates.

The simulation reveals that during the first week of melt starting 27 May, refreezing occurred at all measurement depths within the snowpack (Fig. 5A). The peak refreezing occurred on 30 May and at depths below $0.50 \mathrm{~m}$. During this period the total refreezing rate in the snowpack was comparable to the average melt rate of that first period of melt $(6 \mathrm{~kg}$ $\mathrm{m}^{-2}$ day $^{-1}$; Fig. 5B). The subsequent cold content reduction and thinning snowpack resulted in low refreezing values below $0.4 \mathrm{~kg} \mathrm{~m}^{-2} \mathrm{day}^{-1}$ at all depths. Note that refreezing rates during the sub-freezing early period of our simulation are non-zero and large near the surface. It is possible that shortwave penetration in the snow plays a role or that our conduction model is flawed in conditions of large temperature gradients in well-ventilated, low-density snow, which is valid for the start of the simulation period. However, in terms of total refreezing the early results add up to small values (Fig. 5B). 
The non-zero values of roughly $0.1 \mathrm{~kg} \mathrm{~m}^{-2}$ day $^{-1}$ at greater depth are considered the uncertainty for the entire simulation period.

During the cold period in June, the refreezing rates increased again to $3 \mathrm{~kg} \mathrm{~m}^{-2} \mathrm{day}^{-1}$ (Fig. $5 \mathrm{~B}$ ), which is an indication that liquid water was available, primarily at depths $0.20-0.30 \mathrm{~m}$, while the required cold content was being supplied by the surface. This method of refreezing requires liquid water retention in the snow matrix while cold content becomes available, as opposed to the refreezing of meltwater percolating into layers at sub-freezing temperatures. The heat between $0.60-0.70 \mathrm{~m}$ that was conducted to depths below the seasonal snow layer increased the available cold content, thus when melt occurred again, refreezing was prominent at those depths (15 June; Fig. 5A). As the average melt rate after 13 June was $c .8 \mathrm{~mm}$ w.e. day ${ }^{-1}$, the refrozen water in the snowpack was less than $10 \%$ of this amount, implying liquid water retention or the routing of meltwater to the layers below. Overall, the simulated density increase within the snowpack was between $70-80 \mathrm{~kg} \mathrm{~m}^{-3}$ for most levels.

Meltwater refreezing is a positive component in the mass budget (mass storage; Harper et al. 2012), although in a warming climate with more frequent extreme melt conditions, the larger meltwater fluxes in the snow and firn may result in rapid reduction of pore volume (Van Angelen et al. 2013). The large melt of 2012 at the elevation of KAN_U was a result of both high atmospheric temperatures (Bennartz et al. 2013) and a relatively low albedo from the exposure of the water-saturated firn after the early removal of the relatively thin winter snowpack (Charalampidis et al. 2015). The high ice content of the firn as found during the measurement campaign is an indication of intense percolation during previous years. These snow processes are still quite poorly represented in modelling efforts, also due to the dependency of horizontal meltwater runoff on the ice layers formed by refreezing. Our results illustrate that especially the melt-albedo feedback in relation to pore-volume reduction makes the lower accumulation area of the Greenland ice sheet highly responsive in a warming climate.

\section{Acknowledgements}

The data presented in this paper were gathered in close collaboration with the Greenland Analogue Project. We are grateful to our Snow Processes in the Lower Accumulation Zone project partners Horst Machguth, Mike MacFerrin, Andreas Mikkelsen, Rickard Pettersson, Katrin Lindbäck, Alun Hubbard and Sam Doyle. This is a publication in the framework of the Programme for Monitoring of the Greenland Ice Sheet (PROMICE) and contribution number 63 of the Nordic Centre of Excellence SVALI, 'Stability and Variations of Arctic Land Ice', funded by the Nordic Toplevel Research Initiative (TRI).

\section{References}

Bennartz, R., Shupe, M.D., Turner, D.D., Walden, V.P., Steffen, K., Cox, C.J. Kulie, M.S. Miller, N.B. \& Pettersen, C. 2013: July 2012 Greenland melt extent enhanced by low-level liquid clouds. Nature 496, 83-86.

Box, J.E., Fettweis, X., Stroeve, J.C., Tedesco, M., Hall D.K. \& Steffen, K. 2012: Greenland ice sheet albedo feedback: thermodynamics and atmospheric drivers. The Cryosphere 6, 821-839.

Charalampidis, C. et al. 2015: Changing surface-atmosphere energy exchange and refreezing capacity of the lower accumulation area, west Greenland. The Cryosphere Discussions 9, 2867-2913.

Enderlin, E.M., Howat, I.M., Jeong, S., Noh, M.-J., van Angelen, J.H. \& van den Broeke, M.R. 2014: An improved mass budget for the Greenland ice sheet. Geophysical Research Letters 41, 866-872.

Harper, J., Humphrey, N., Pfeffer, W.T., Brown, J. \& Fettweis, X. 2012: Greenland ice-sheet contribution to sea-level rise buffered by meltwater storage in firn. Nature 491, 240-243.

Humphrey, N.F., Harper, J.T. \& Pfeffer, W.T. 2012: Thermal tracking of meltwater retention in Greenland's accumulation area. Journal of Geophysical Research: Earth Surface 117, F01010.

Nghiem, S.V., Hall, D.K., Mote, T.L., Tedesco, M., Albert, M.R., Keegan, K., Shuman, C.A., DiGirolamo, N.E. \& Neumann, G. 2012: The extreme melt across the Greenland ice sheet in 2012. Geophysical Research Letters 39, L20502.

Shepherd, A. et al. 2012: A reconciled estimate of ice-sheet mass balance. Science 338, 1183-1189.

Sturm, M., Holmgren, J., König, M. \& Morris, K. 1997: The thermal conductivity of seasonal snow. Journal of Glaciology 43, 26-41.

Van Angelen, J.H., Lenaerts, J.T.M., van den Broeke, M.R., Fettweis, X. \& Meijgaard, E. 2013: Rapid loss of firn pore space accelerates 21st century Greenland mass loss. Geophysical Research Letters 40, 2109-2113.

Van As, D., Fausto, R.S., Colgan, W.T., Box, J.E. \& the PROMICE project team 2013: Darkening of the Greenland ice sheet due to the melt-albedo feedback observed at the PROMICE weather stations. Geological Survey of Denmark and Greenland Bulletin 28, 69-72.

Van As, D. et al. 2014: Increasing meltwater discharge from the Nuuk region of the Greenland ice sheet and implications for mass balance (1960-2012). Journal of Glaciology 60, 314-322.

Yen, Y.C. 1981: Review of thermal properties of snow, ice and sea ice. CRREL Report 81-10, 27 pp. Hanover, New Hampshire: US Army Corps of EngineersCold Regions Research and Engineering Laboratory.

Authors' addresses

C.C.* \& D.v.A., Geological Survey of Denmark and Greenland, Øster Voldgade 10, DK-1350 Copenhagen K, Denmark. E-mail: cc@geus.dk

*Also at: Department of Earth Sciences, Uppsala University, Villavägen 16, 75236 Uppsala, Sweden. 